\title{
A Peculiar Type of Haemangioma that Poses Some Problems in Pathological Differential Diagnosis with Angiosarcoma
}

\author{
Nataniele Piol ${ }^{1 *}$, Gabriele Gaggero ${ }^{1}$, Carlo Terrone ${ }^{2}$, Guglielmo Mantica ${ }^{2}$ and Bruno Spina ${ }^{1}$ \\ ${ }^{1}$ Department of Anatomic Pathology, Ospedale Policlinico San Martino, Genoa, Italy \\ ${ }^{2}$ Department of Urology, Ospedale Policlinico San Martino, Genoa, Italy
}

*Corresponding author: Nataniele Piol, Department of Anatomic Pathology, Ospedale Policlinico San Martino, Genoa, Italy

\begin{tabular}{|c|c|}
\hline ARTICLE INFO & ABSTRACT \\
\hline Received: 幽 September 26, 2021 & $\begin{array}{l}\text { Vascular tumors are predominantely superficial lesions spanning from benign } \\
\text { through intermediate grade to malignant neoplasm with various histological appearance }\end{array}$ \\
\hline Published: 幽 October 04, 2021 & $\begin{array}{l}\text { and subtypes. Deep seated vascular lesions, especially in retroperitoneum, are usually } \\
\text { angiosarcomas. Anastomising hemangioma is a rare benign neoplasm originally }\end{array}$ \\
\hline $\begin{array}{l}\text { tation: Nataniele Piol, Gabriele Gag- } \\
\text { ro, Carlo Terrone, Guglielmo Mantica, } \\
\text { uno Spina. A Peculiar Type of Hae- }\end{array}$ & $\begin{array}{l}\text { was subsequently found in other sites, retroperitoneum being one of the least common. } \\
\text { In particular we herein report a case of anastomosing hemangioma in perirenal adipose } \\
\text { tissue. }\end{array}$ \\
\hline
\end{tabular}
mangioma that Poses Some Problems in Pathological Differential Diagnosis with Angiosarcoma. Biomed J Sci \& Tech Res 39(2)-2021. BJSTR. MS.ID.006265.

Keywords: Kidney; Peri-Renal; Anastomosing Hemangioma; Hemangioma; Angiosarcoma

\section{Introduction}

Anastomising hemangioma is a rare benign neoplasm originally described in urogenital organs [1]. Even if it is seldom encountered in routine diagnostic sign out, it is important for pathologist to know about its existence because it has quite alarming histological features that could lead to an erroneous diagnosis of angiosarcoma. After its original description, this neoplasm was subsequently found in other sites, retroperitoneum being one of the least common [2], especially without any concomitant renal lesion.

We herein report a rare case of retroperitoneal anastomosing hemangioma.

\section{Case Report}

A 49-years old male patient came to our attention in January 2019 for the incidental finding of a 16×12 mm right peri-renal lesion at the superior abdominal images of a chest computed tomography
(CT) scan. The patient had a positive medical history for pulmonary tuberculosis and asthma. He did not complain of hematuria, flank pain or any other symptom. An abdominal contrast CT scan was performed, which confirmed the presence of the abovementioned lesion (Figure 1). A $5 \times 7,8 \mathrm{~cm}$ hepatic hemangioma completed the scenario. The patient also underwent a positron emission tomography with fluorodeoxyglucose (18F-FDG-PET) scan which did not find an increased glucose metabolism. At the presentation the patient had haemoglobin $16,2 \mathrm{~g} / \mathrm{dl}$, creatinine $1,3 \mathrm{mg} / \mathrm{dl}$.

The patient underwent a laparoscopic exeresis of right peri-renal lesion with preservation of the kidney and adrenal gland. No postoperative complications were observed. Perirenal fat tissue including the above-mentioned lesion was sent to Anatomic Pathology Laboratory and fixed overnight in $10 \%$ formalin. Gross examination of perirenal fat tissue revealed a 
reddish nodule measuring $16 \times 12 \mathrm{~mm}$, which was totally submitted for histological examination, routinely processed and paraffin embedded. Histological sections were cut at 4 micrometer thickness and routinely stained using hematoxylin and eosin (H\&E). Immunohistochemical stains were subsequently performed with commercially ready for use antibodies (CD34, clone QBEnd/10, Ventana; CD31, clone JC70, Cell Marque; FLI-1, clone MRQ1, Cell Marque; Ki-67, clone 30-9, Ventana) on formalin fixed, paraffin embedded sections using an automated immunostainer (Benchmark Ultra; Ventana; USA).

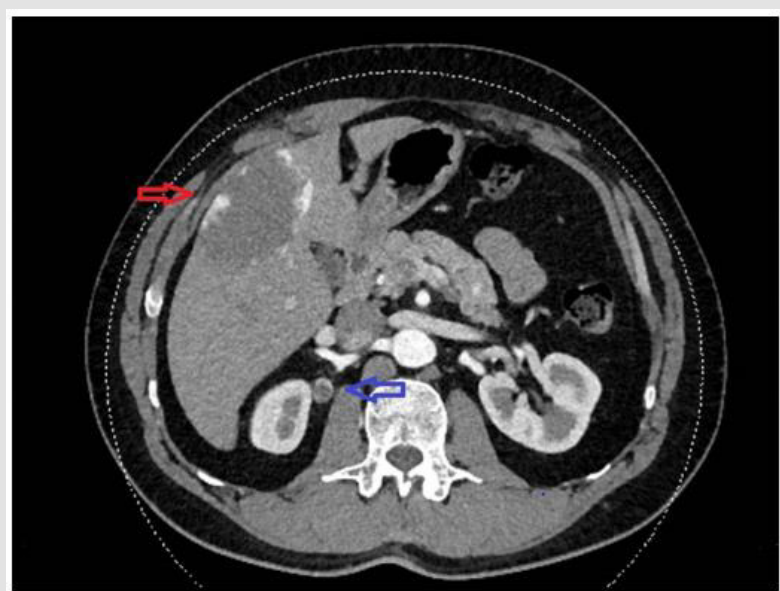

Figure 1: Abdominal CT scan showing a 16x12 mm right peri-renal lesion (blue arrow) and hepatic hemangioma (red arrow).

Microscopic examination showed a circumscribed hyalinization and hemorrhages; occasional intravascular thrombi unencapsulated vascular lesion featuring a central hypocellular and could be seen. On immunohistochemistry, endothelial cells showed edematous core surrounded by a more cellular area composed of expression of CD31, CD34 and FLI-1. Proliferation index evaluated ectatic and variably anastomizing thin-walled blood vessels. They with Ki-67 was very low (Figure 2). Morphological findings were were lined by endothelial cells sometimes with hobnail appearance thus consistent with an anastomosing hemangioma. but without aypia, multilayering or mitoses. There were stromal

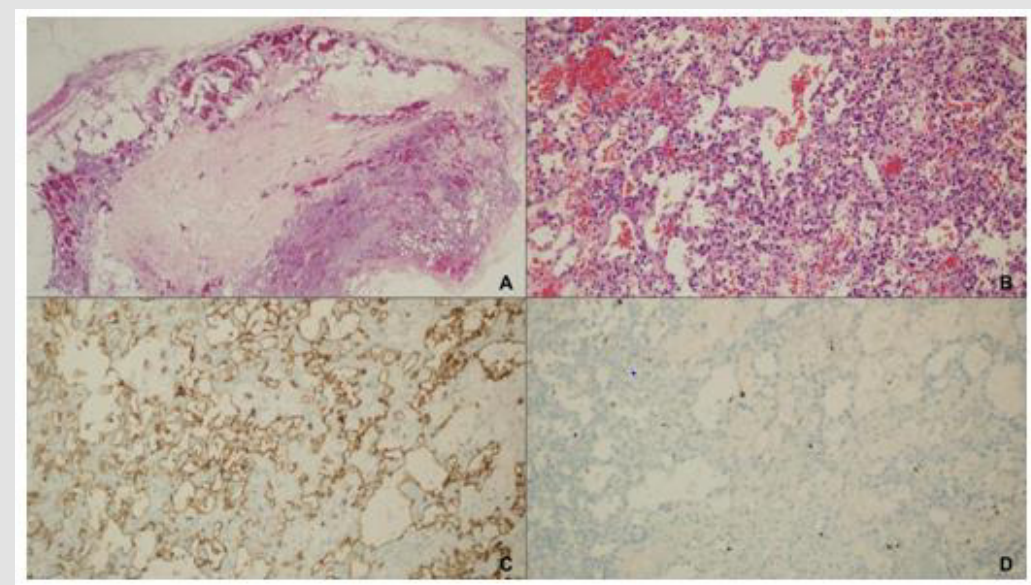

Figure 2: On microscopic examination a well-circumscribed, unencapsulated lesion was found (A: H\&E, 40x). This lesion has a central hypocellular and edematous area surrounded by a cellular area composed of anastomizing thin-walled blood vessels lined by endothelial cells without features of malignancy (B: H\&E, 200x). On immunohistochemistry, endothelial cells showed expression of CD31 (C: CD31 immunostain, 200x). Proliferation index evaluated with Ki-67 was very low (D: Ki-67 immunostain, 200x).

\section{Discussion}

Vascular tumors can be benign, can have a locally aggressive but rarely metastasizing behaviour (so-called intermediate-grade vascular tumors) or can be highly aggressive with local and distant spread (angiosarcomas). Most of them are superficially located on the skin and in the subcutaneous tissue but they can also develop in deep-seated soft tissues and in internal organs. They are more 
common in children and young adults, even if some exception occurs $[3,4]$. Among benign tumors a wide variety of histotypes are described. Anastomosing hemangioma have some peculiarities: it tends to occur in adults with a preference for deep localization [2]. In fact, it was first described in 2009 as a peculiar vascular lesion mimicking angiosarcoma and involving kidney and testis [1]. A recent review [5] have collected about 60 cases renal cases, and an approximately equal number of non-renal lesions, the most frequent of which are the soft tissues and the bones, especially in paraspinal locations [2].

Occurence in perirenal fat without involvement of the kidney is very unusual. At the best of our knowledge only six cases were previously reported exclusively in peri-renal fat [6-8] without concomitant kidney involvement. The anastomizing structure, the diffuse (i.e. non-lobular) pattern of growth and the hobnail appearance of endothelial cells which can show mild atypia may be quite alarming for the differential diagnosis with a welldifferentiated angiosarcoma, especially on small biopsies. Moreover, the lesion frequently has some infiltrative pattern at the edge, which can be misinterpreted as an additional sign of malignancy. However, the absence of mitoses, multilayering, overt atypia and extensive destructive infiltrative pattern may suggest the right diagnosis. Moreover, the homogeneity of the lesion, without any poorly differentiated area stands against a diagnosis of malignancy $[5]$.

\section{Conclusion}

In conclusion, anastomizing hemangioma is a rare lesion with less than one hundred cases reported in ten years. However, it usually occurs at any deep location and with worrisome clinical

\section{ISSN: 2574-1241}

DOI: 10.26717/BJSTR.2021.39.006265

Nataniele Piol. Biomed J Sci \& Tech Res

This work is licensed under Creative Commons Attribution 4.0 License

Submission Link: https://biomedres.us/submit-manuscript.php and microscopic features that could lead to a wrong diagnosis of malignant vascular tumor, so pathologists and uropathologists should be well aware of its existence.

\section{Conflicts of Interest}

The authors declare no potential conflicts of interest with respect to research, authorship, and/or publication of this article.

\section{Acknowledgement}

None.

\section{References}

1. Montgomery E, Epstein JI (2009) Anastomosing hemangioma of the genitourinary tract: a lesion mimicking angiosarcoma. Am J Surg Pathol 33: 1364-1369.

2. John I, Folpe AL (2016) Anastomosing hemangiomas arising in unusual locations. Am J Surg Pathol 40: 1084.

3. In: Elder DE, Massi D, Scolyer RA, Willemze R (Eds.)., WHO Classification of Skin Tumours ( $4^{\text {th }}$ Edn.)., Lyon:IARC.

4. In: Fletcher CDM, Bridge JA, Hogendoorn PCW, Mertens F (Eds.)., (2013) WHO Classification of Tumours of Soft Tissue and Bone ( $4^{\text {th }}$ Edn.)., Lyon:IARC.

5. Lappa E, Drakos E (2020) Anastomosing hemangioma. Arch Pathol Lab Med 144(2): 240-244.

6. Kryvenko ON, Gupta NS, Meier FA, Lee MW, Epstein JI (2011) Anastomosing hemangioma of the genitourinary system: eight cases in the kidney and ovary with immunohistochemical and ultrastructural analysis. Am J Clin Pathol 136(3): 450-457.

7. O'Neill AC, Craig JW, Silverman SG, Alencar RO (2016) Anastomosing hemangiomas: locations of occurrence, imaging features, and diagnosis with percutaneous biopsy. Abdom Radiol (NY) 41: 1325-1324.

8. Kishida N, Sentani K, Terada H, Honda Y, Goto K, et al. (2017) Anastomosing haemangioma with fatty changes in the perirenal space: a lesion mimicking liposarcoma. BJR Case Rep 4(2): 20170022.

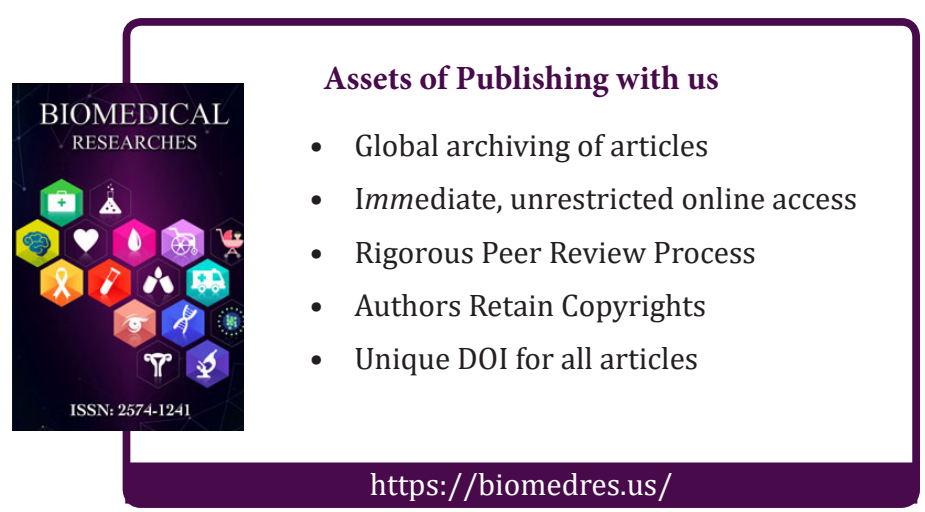

